\title{
Effects of abdominal massage on gastrointestinal function in ICU patients: a meta-analysis
}

Original article

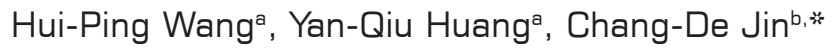 \\ ${ }^{a}$ Graduate School of Tianjin University of Traditional Chinese Medicine, Tianjin 301617, China \\ ${ }^{b}$ Tianjin University of Traditional Chinese Medicine, Tianjin 301617, China
}

Received: 6 May 2019; Accepted: 2 July 2019; Published: 20 December 2019

\begin{abstract}
Objective: To evaluate the effects of abdominal massage on gastrointestinal function in the intensive care unit (ICU) patients.
Methods: Randomized controlled trials about the effects of abdominal massage on gastrointestinal function in ICU patients were included from multiple electronic databases: PubMed, Web of Science, the Cochrane Library, Embase, CINAHL, China Academic Journals Full-Text Database (CNKI), Wanfang Database, and CQVIP, until November 2018. Studies were selected according to inclusion and exclusion criteria, extracting data and assessing. Data were analyzed by RevMan 5.3.

Results: Nine studies with 720 patients were included. The results of meta-analysis in the intervention group were as follows: abdomen circumference: mean difference $(\mathrm{MD})=-4.22,95 \%$ confidence interval $(\mathrm{Cl})=(-6.20,-2.24), P<0.00001$; abdominal distension: $\mathrm{MD}=0.34,95 \% \mathrm{Cl}=(0.22,0.52), P<0.00001$; gastric residual: $\mathrm{MD}=-41.51,95 \% \mathrm{Cl}=(-55.86,-29.15), P=0.001$; gastric retention: $\mathrm{MD}=-0.23,95 \% \mathrm{Cl}(-0.30,-0.15), P<0.00001$; and vomiting: $\mathrm{MD}=0.12,95 \% \mathrm{Cl}=(0.04,0.35), P=0.0001$. Conclusions: Abdominal massage is effective in reducing abdominal distension, gastric residual, and vomiting. When the intervention period was $<7$ days, abdominal massage could not reduce the abdominal circumference in ICU patients, and when the intervention period was equal to 7 days, abdominal massage could reduce the abdominal circumference in ICU patients.
\end{abstract}

Keywords: abdominal massage • ICU • meta-analysis • gastrointestinal function • gastrointestinal tract

(c) Shanxi Medical Periodical Press.

\section{Introduction}

Gastrointestinal dysfunction is one of the major problems faced by the intensive care unit (ICU) patients. If patients do not have enough calories intake each day, they may suffer from malnutrition and other problems. ${ }^{1}$ In non-drug therapy, abdominal massage with low price and few side effects is widely used in patients with gastrointestinal dysfunction as an auxiliary care. ${ }^{2}$ However, relevant studies have shown that whether abdominal massage can improve gastrointestinal dysfunction in patients is inconsistent. In one study, patients in the experimental group showed no significant difference in gastric residual volume $;^{3,4}$ the rate of the abdominal distension ${ }^{5}$ was compared in patients after abdominal

How to cite this article: Wang HP, Huang YQ, Jin CD. Effects of abdominal massage on gastrointestinal function in ICU patients: a meta-analysis. Front Nurs. 2019; 4: 349-356. 
massage with those in the control group. However, other studies have found that intraperitoneal massage can reduce gastric residual volume (GRV) in ICU patients ${ }^{4,6}$ and prevent neonatal vomiting and improve gastrointestinal function. ${ }^{7}$

\section{Materials and methods}

\subsection{Inclusion and exclusion}

The inclusion criteria were as follows. Randomized controlled trials (RCTs) were included. The language was limited to Chinese and English.

The following patients were excluded: patients with no abdominal radiotherapy and abdominal surgery performed in the past 6 weeks; patients with abdominal contraindications, such as abdominal tumor, peritonitis, ascites, and ileus; patients with congenital malformation, such as congenital heart disease and abnormal digestive tract; and neonates fed with gastrostomy tubes.

\subsection{Participants}

Participants were patients in the ICU.

\subsection{Intervention}

The experimental group received abdominal massage on the basis of the same intervention measures as the control group. The control group received conventional care.

\subsection{Outcome}

Gastric residue, abdominal circumference, the incidence of gastric retention, bloating, and vomiting were assessed.

\subsection{Search strategy}

We carried on a comprehensive search of the literature in five English databases: (PubMed, Web of Science, the Cochrane Library, Embase, and AMED) and four Chinese databases (CBM, CNKI, Wanfang, and VIP), which have been searched from their establishment to November 2018.

The Chinese search strategy was "ComalCUN ICU Intensive care unit premie low birth weight infant" AND "swaddle swaddling". The English search strategy was "abdominal massage*". We used the following subject words, free words, and Boolean logic operators when searching. Computer retrieval was the main method, supplemented by manual retrieval. In the retrieved literature, the second extended retrieval was carried out to avoid the omission of literature, and the quality evaluation of the included literature was carried out.

\subsection{Data extraction}

There were two reviewers screened independently according to the inclusion and exclusion criteria. From each included study, data were extracted independently. Study characteristics (eg, author and year), study design, sample size, description of interventions, and indexes of assessed outcomes were sorted using a data extraction form. If two researchers disagree on the quality of the study, a third nursing professor with a PhD arbitrated.

\subsection{Data analysis}

Meta-analysis was conducted using the RevMan 5.3 software. When meta-analysis was conducted for continuous variables, data were described and expressed as mean difference (MD) or standard mean difference (SMD) with 95\% confidence interval (Cl). If significant heterogeneity did not exist among studies $\left(R^{2} \leq 50 \%, P \geq 0.1\right)$, a fixed effect model was established in the meta-analysis. If significant heterogeneity existed among studies $\left(I^{2}>50 \%, P<0.1\right)$, the source of the heterogeneity was analyzed. If only statistical heterogeneity was observed among the studies, without clinical heterogeneity, a randomized effect model was constructed. Descriptive analysis was conducted if the heterogeneity was too obvious and the source could not be determined.

\section{Result}

For the first time, 842 related reports were detected, including 250 in Chinese and 574 in English. After reading the title and abstract, 794 articles were excluded, including duplicates, reviews, case reports and inconsistencies with the theme by EndNote. By searching and reading the full text, 17 articles on combined intervention, two articles on CCT, and one article on peer review were further excluded. Finally, nine papers (five in English and four in Chinese) with 720 patients were included.

\subsection{Basic characteristics and methodological quality evaluation of included studies}

The basic characteristics of the included studies are given in Table 1. According to the Cochrane risk of bias 


\begin{tabular}{|c|c|c|c|c|c|c|c|}
\hline \multirow{2}{*}{ Study } & \multicolumn{2}{|c|}{ Age (years) } & \multicolumn{2}{|c|}{ Sample } & \multicolumn{2}{|l|}{ Intervention } & \multirow{2}{*}{ Outcome } \\
\hline & I & $\mathrm{C}$ & I & $C$ & I & $\mathrm{C}$ & \\
\hline $\begin{array}{l}\text { Dehghan et al. } \\
2018^{4}\end{array}$ & $40.94 \pm 19.44$ & $42.97 \pm 23.08$ & 35 & 35 & $\begin{array}{l}\text { Conventional nursing; abdominal } \\
\text { massage: touch, massage, knead, } \\
\text { and vibrate; twice a day for } 15 \text { min } \\
\text { each time, last } 3 \text { days }\end{array}$ & $\begin{array}{l}\text { Conventional } \\
\text { nursing }\end{array}$ & $\begin{array}{l}\text { Abdominal circumference, } \\
\text { defecation, constipation }\end{array}$ \\
\hline $\begin{array}{l}\text { Momenfar et al. } \\
2018^{6}\end{array}$ & $60.76 \pm 17.38$ & $58.66 \pm 14.75$ & 30 & 30 & $\begin{array}{l}\text { Conventional nursing; abdominal } \\
\text { massage: touch, massage, knead, } \\
\text { and vibrate; twice a day for } 20 \text { min } \\
\text { each time, last } 3 \text { days }\end{array}$ & $\begin{array}{l}\text { Conventional } \\
\text { nursing }\end{array}$ & Gastric residual \\
\hline Shaeri et al. $2017^{9}$ & Unclear & Unclear & 50 & 50 & $\begin{array}{l}\text { Conventional nursing; abdominal } \\
\text { massage: touch, massage, knead, } \\
\text { and vibrate; twice a day for } 15 \text { min } \\
\text { each time, last } 3 \text { days }\end{array}$ & $\begin{array}{l}\text { Conventional } \\
\text { nursing }\end{array}$ & $\begin{array}{l}\text { Gastric residual, abdominal } \\
\text { distension, vomiting, } \\
\text { abdominal circumference }\end{array}$ \\
\hline $\begin{array}{l}\text { Kahraman and } \\
\text { Ozdemir } 2015^{10}\end{array}$ & $70.4 \pm 13.0$ & $70.4 \pm 13.0$ & 16 & 16 & $\begin{array}{l}\text { Conventional nursing; abdominal } \\
\text { massage: touch, massage, knead, } \\
\text { and vibrate; twice a day for } 15 \text { min } \\
\text { each time, last } 3 \text { days }\end{array}$ & $\begin{array}{l}\text { Conventional } \\
\text { nursing }\end{array}$ & $\begin{array}{l}\text { Gastric residual, abdominal } \\
\text { circumference, ventilator- } \\
\text { associated pneumonia }\end{array}$ \\
\hline Uysal et al. $2012^{11}$ & More than 18 & More than 18 & 40 & 40 & $\begin{array}{l}\text { Conventional nursing; abdominal } \\
\text { massage: touch, massage, knead, } \\
\text { and vibrate; twice a day for } 15 \text { min } \\
\text { each time, last } 3 \text { days }\end{array}$ & $\begin{array}{l}\text { Conventional } \\
\text { nursing }\end{array}$ & $\begin{array}{l}\text { Gastric retention, gastric } \\
\text { retention, abdominal } \\
\text { distension, vomiting, } \\
\text { ventilator-associated } \\
\text { pneumonia }\end{array}$ \\
\hline Huang $2017^{12}$ & $63.0 \pm 12.2$ & $62.7 \pm 12.6$ & 49 & 49 & $\begin{array}{l}\text { Conventional nursing; abdominal } \\
\text { massage: touch, massage, knead, } \\
\text { and vibrate; three times a day for } \\
15 \text { min each time, last } 7 \text { days }\end{array}$ & $\begin{array}{l}\text { Conventional } \\
\text { nursing }\end{array}$ & $\begin{array}{l}\text { Retention, abdominal } \\
\text { circumference, adverse } \\
\text { reactions }\end{array}$ \\
\hline Lyu et al. $2014^{13}$ & More than 18 & More than 18 & 40 & 40 & $\begin{array}{l}\text { Conventional nursing; abdominal } \\
\text { massage: touch, massage, knead, } \\
\text { and vibrate; three times a day for } \\
15 \text { min each time, last } 7 \text { days }\end{array}$ & $\begin{array}{l}\text { Conventional } \\
\text { nursing }\end{array}$ & $\begin{array}{l}\text { Gastric retention, abdominal } \\
\text { circumference, abdominal } \\
\text { distension, vomiting }\end{array}$ \\
\hline Ge et al. $2013^{14}$ & $60.3 \pm 10.2$ & $58.4 \pm 13.5$ & 52 & 56 & $\begin{array}{l}\text { Conventional nursing; abdominal } \\
\text { massage: touch, massage, knead, } \\
\text { and vibrate; three times a day for } \\
15 \text { min each time, last } 7 \text { days }\end{array}$ & $\begin{array}{l}\text { Conventional } \\
\text { nursing }\end{array}$ & $\begin{array}{l}\text { Abdominal circumference, } \\
\text { abdominal distension, } \\
\text { gastric retention }\end{array}$ \\
\hline Zhou et al. $2016^{15}$ & 29-84 & $29-84$ & 46 & 46 & $\begin{array}{l}\text { Conventional nursing; abdominal } \\
\text { massage: press, gently lift, press, } \\
\text { cycle massage; three times a day } \\
\text { for } 15 \text { min each time, last } 7 \text { days }\end{array}$ & $\begin{array}{l}\text { Conventional } \\
\text { nursing }\end{array}$ & $\begin{array}{l}\text { Vomiting, abdominal } \\
\text { distension, diarrhea }\end{array}$ \\
\hline
\end{tabular}

Note: RCT: randomized controlled trial; I: intervention group; C: control group.

Table 1. Basic characteristics of included RCT studies

estimation, generation of allocation sequence in every trial is mentioned. ${ }^{8}$ Among the nine included articles the quality was $B$. Because the intervention in this study was abdominal massage, the participants could not be blinded (excluding coma patients and premature infants). So, it was rated as high risk of bias (Table 2).

\subsection{Meta-analysis results}

\subsubsection{Effect of abdominal massage on abdominal circumference}

Five articles ${ }^{4,10,12-14}$ reported the effect of abdominal massage on abdominal circumference. The results showed heterogeneity between studies $(P<0.00001$; $\left.R^{2}=90 \%\right)$. The reasons for the analysis of heterogeneity may be related to the cycle of intervention, so we did a subgroup analysis. The results were divided into two groups for subgroup analysis according to the intervention period less than 7 days and the intervention period equal to 7 days. The results showed that when the intervention time of abdominal massage was $<7$ days, there was no significance between the intervention group and control group $(P>0.05)$. However, when the intervention period was equal to 7 days, there was significance $(P>0.05)$ between the two groups (Figure 1).

\subsubsection{Effects of abdominal massage on gastric residue}

Seven articles ${ }^{4,6,9,11-14}$ reported the effects of abdominal massage on gastric residue. The results showed that there was no heterogeneity between studies, so a fixedeffect model was used for meta-analysis. The results 
showed that the gastric residue in the abdominal massage group was lower than that in the control group, and the difference between the two groups was statistically significant $[\mathrm{MD}=-39.76,95 \% \mathrm{Cl}(-48.01,-31.33)$, $P=0.00001$; Figure 2].

\subsubsection{Effects of abdominal massage on the incidence of gastric retention}

Three articles $9,11,14$ reported the effects of abdominal massage on gastric retention. The results showed that

\begin{tabular}{|c|c|c|c|c|c|c|c|c|}
\hline \multirow{2}{*}{ Study } & \multirow{2}{*}{$\begin{array}{l}\text { Random } \\
\text { sequence }\end{array}$} & \multirow{2}{*}{$\begin{array}{l}\text { Allocation } \\
\text { concealment }\end{array}$} & \multicolumn{2}{|c|}{ Blinded } & \multirow{2}{*}{$\begin{array}{l}\text { Data } \\
\text { integrity }\end{array}$} & \multirow{2}{*}{$\begin{array}{l}\text { Report } \\
\text { results }\end{array}$} & \multirow{2}{*}{$\begin{array}{l}\text { Other } \\
\text { biases }\end{array}$} & \multirow{2}{*}{ Quality } \\
\hline & & & (1) & (2) & & & & \\
\hline Momenfar et al. $2018^{6}$ & Unclear & Low risk & High risk & Low risk & Unclear & Low risk & Unclear & $\mathrm{B}$ \\
\hline Dehghan et al. $2018^{4}$ & High risk & Unclear & High risk & Low risk & High risk & Low risk & Low risk & B \\
\hline Uysal et al. $2017^{9}$ & High risk & High risk & Low risk & Low risk & Low risk & Low risk & Low risk & B \\
\hline Kahraman and Ozdemir $2015^{10}$ & High risk & High risk & High risk & Low risk & Low risk & Low risk & Low risk & B \\
\hline Uysal et al. $2012^{11}$ & High risk & High risk & Low risk & Low risk & Low risk & Low risk & Low risk & $\mathrm{B}$ \\
\hline Huang $2017^{12}$ & Unclear & Unclear & High risk & Low risk & Low risk & Low risk & Low risk & B \\
\hline Lyu et al. $2014^{13}$ & Low risk & Unclear & High risk & Low risk & Low risk & Low risk & Low risk & $\mathrm{B}$ \\
\hline Ge et al. $2013^{14}$ & Unclear & Unclear & High risk & Low risk & High risk & Low risk & Low risk & B \\
\hline Zhou et al. $2016^{15}$ & Unclear & Unclear & Low risk & Low risk & Low risk & Low risk & Low risk & B \\
\hline
\end{tabular}

Note: (1): Blind study participants or intervention implementers; (2): Blind outcome evaluators.

Table 2. Methodological quality evaluation of included studies.

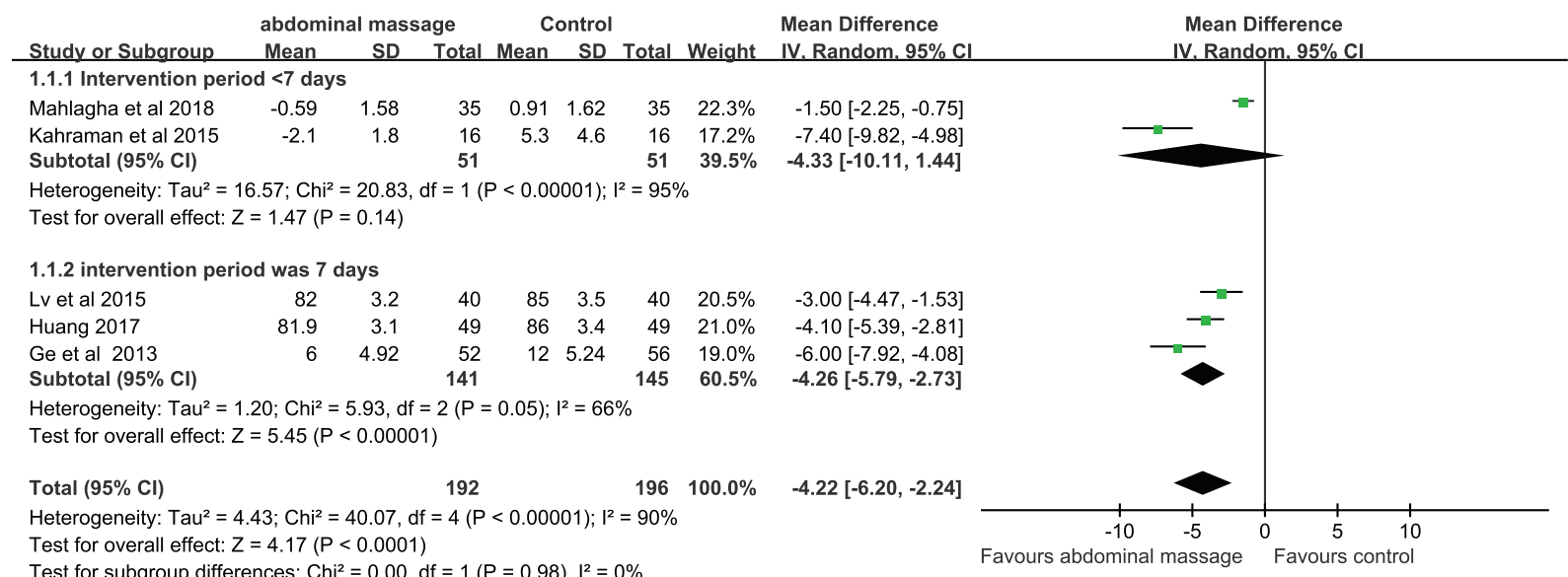

Figure 1. Subgroup analysis of the effects of abdominal massage on the abdominal circumference in ICU patients.

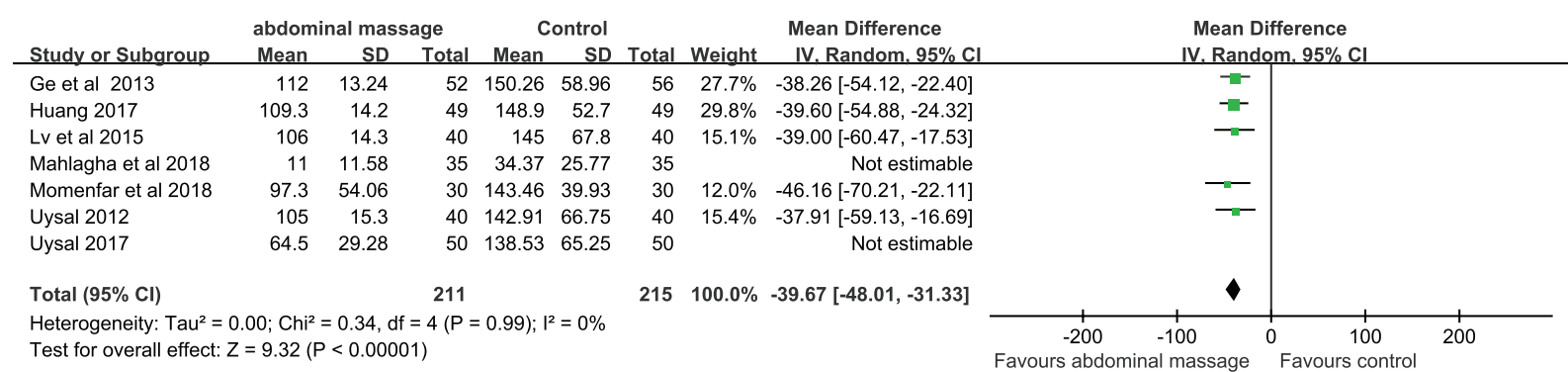

Figure 2. Forest plot of gastric residue. 
there was no heterogeneity between studies, so a fixedeffect model was used for meta-analysis. The results showed that the incidence of gastric retention was lower in the abdominal massage group than that in the control group, and the difference between the two groups was statistically significant $[\mathrm{MD}=-0.23,95 \% \mathrm{Cl}(-0.30$, $-0.15), P<0.00001$; Figure 3].

\subsubsection{Effects of abdominal massage on the incidence of abdominal distension}

Six articles ${ }^{9,11-15}$ reported the influence of abdominal massage on the incidence of abdominal distension. The results showed that there was no heterogeneity between studies $\left(P=0.66 ; P^{2}=0 \%\right)$, so a fixed-effect model was used for meta-analysis. The results showed that the incidence of abdominal distension in the abdominal massage group was lower than that in the control group, and the difference in the incidence of abdominal distension between the two groups was statistically significant $[\mathrm{MD}=0.34,95 \% \mathrm{Cl}(0.22,0.52), P<0.00001$; Figure 4]

\subsubsection{Effect of abdominal massage on the incidence of vomiting}

Six articles ${ }^{9,11-14}$ reported the effects of abdominal massage on the incidence of vomiting $(P=1.00 ; R=0 \%)$, so a fixed-effects model was used for meta-analysis. The results showed that the incidence of vomiting in the abdominal massage group was lower than that in the control group, and the difference between the two groups was statistically significant $[\mathrm{MD}=0.12,95 \% \mathrm{Cl}$ (0.04, 0.35), $P=0.0001$; Figure 5].

\section{Discussion}

\subsection{Methodological quality evaluation of included studies}

A total of nine articles were included. The quality grades of all articles were $\mathrm{B}$, and the overall quality was moderate. This may be related to the inconsistency of the randomized design of the included studies and the lack of attention to blindness. One of the included studies ${ }^{13}$ was grouped by the random number method. Although randomization was mentioned in the other studies, ${ }^{4,6,9-12,14,15}$ the specific grouping method was unclear. One study ${ }^{6}$ used allocation hiding. Because the outcome indicators were objective, it had little influence on the evaluation of the results, although the outcome evaluators were not blinded. Therefore, they were still judged as "low risk". In addition, the baseline included in the study was comparable.

\subsection{Evaluation of the effects of abdominal massage on gastrointestinal function in ICU patients}

Six articles in this study showed that abdominal massage can reduce the incidence of abdominal distension. At the same time, the results of this study showed that abdominal massage could not reduce the abdominal circumference in the ICU when the intervention period was

\begin{tabular}{|c|c|c|c|c|c|c|c|c|}
\hline Study or Subgroup & $\begin{array}{c}\text { abdominal massage } \\
\text { Events } \quad \text { Total }\end{array}$ & $\begin{array}{l}\text { Contr } \\
\text { Events }\end{array}$ & $\begin{array}{l}\text { ol } \\
\text { Total }\end{array}$ & Weight & $\begin{array}{c}\text { Risk Difference } \\
\text { M-H, Random, } 95 \% \mathrm{Cl}\end{array}$ & $\begin{array}{r}\text { Risk Dif } \\
\text { M-H, Rand }\end{array}$ & $\begin{array}{l}\text { ifference } \\
\text { dom. } 95 \% \mathrm{Cl}\end{array}$ & \\
\hline Ge et al 2013 & 52 & 16 & 56 & $37.4 \%$ & $-0.25[-0.38,-0.12]$ & & & \\
\hline Uysal 2012 & 40 & 8 & 40 & $35.3 \%$ & $-0.18[-0.31,-0.04]$ & & & \\
\hline Uysal 2017 & 50 & 17 & 50 & $27.3 \%$ & $-0.26[-0.41,-0.11]$ & & & \\
\hline Total $(95 \% \mathrm{Cl})$ & 142 & & 146 & $100.0 \%$ & $-0.23[-0.30,-0.15]$ & & & \\
\hline Total events & 7 & 41 & & & & & & \\
\hline $\begin{array}{l}\text { Heterogeneity: } \mathrm{Tau}^{2} \\
\text { Test for overall effect }\end{array}$ & $\begin{array}{l}0.00 ; C h i^{2}=0.89, d f=2( \\
Z=5.58(P<0.00001)\end{array}$ & $=0.64)$ & $1^{2}=0 \%$ & & & -0.5 & 0.5 & 1 \\
\hline
\end{tabular}

Figure 3. Forest plot of the incidence of gastric retention.

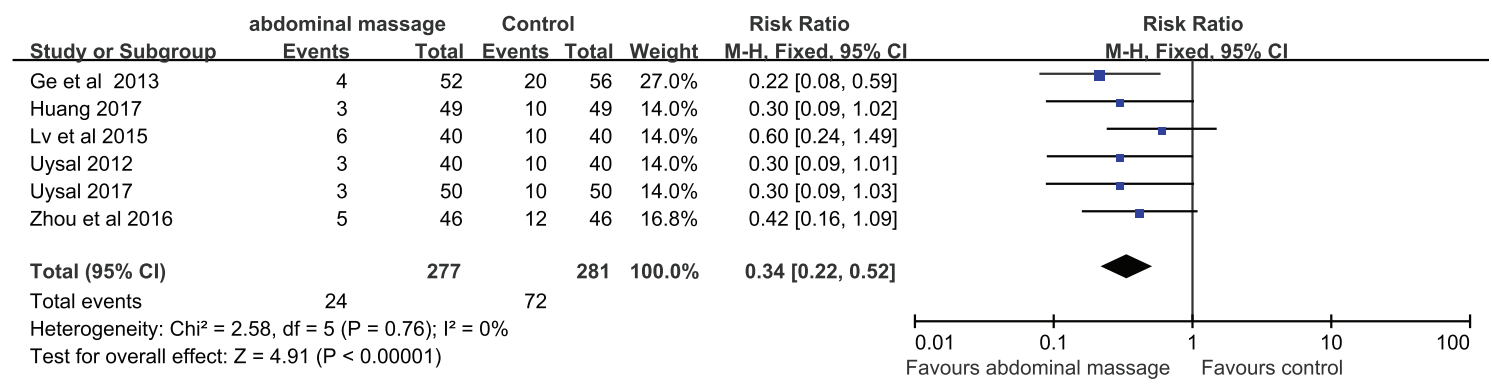

Figure 4. Forest plot of the incidence of abdominal distension. 


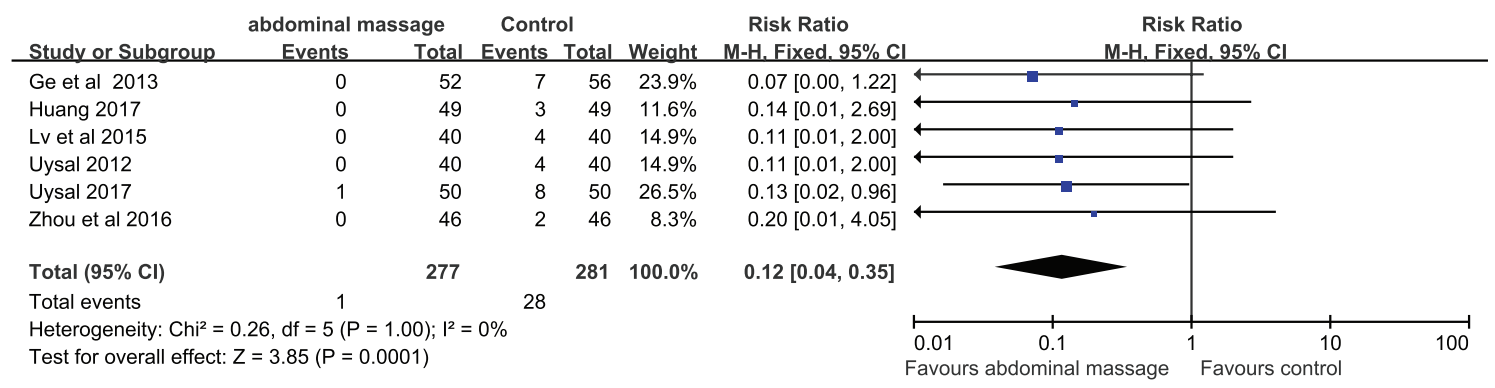

Figure 5. Forest plot of the incidence of vomiting.

$<7$ days, and it could reduce the abdominal circumference in the ICU when the intervention period was equal to 7 days. Patients in the ICU often need a long period of bed rest due to their serious illness, so their peristaltic function is poor and the incidence of adverse reactions is high. Abdominal massage is a safe, convenient, economical, simple, and effective non-drug nursing method..$^{16}$ It can reduce the incidence of abdominal distension by changing the intra-abdominal pressure and accelerating the gastrointestinal peristalsis to produce mechanical reflex effect on the intestinal tract. ${ }^{17-19}$ At the same time, abdominal massage can stimulate the skin sense of touch and pressure receptors produce sympathetic stimulation to promote gastrin secretion to promote gastric peristalsis and reduce abdominal distention. ${ }^{20}$

\subsection{Analysis of the effects of abdominal massage on gastric residual and gastric retention}

Seven literatures included in this study showed that abdominal massage can reduce gastric residual in ICU patients. Three of the articles showed that abdominal massage can reduce gastric retention rate. Multiple studies have found an incidence of GRV of $28.2 \%,{ }^{21}$ $29 \%,{ }^{22} 32 \%{ }^{23}$, and $39 \%{ }^{24}$ in ICU patients. GRV is an important factor affecting gastric emptying speed in ICU patients. ${ }^{6}$ Controlling and reducing GRV is an important measure to improve the nutritional status and reduce complications and the incidence of malnutrition in ICU patients. ${ }^{25,26}$ Abdominal massage had a good effect to reduce the amount of gastric residue and reduce the incidence of gastric retention. It plays an important role in the intake and absorption of nutrients in patients too.

\subsection{Analysis of the effects of abdominal massage on the incidence of vomiting}

Six articles were included in this study that showed that abdominal massage can reduce the incidence of vomiting. Vomiting is one of the most serious complications in ICU patients, which increased the risk of aspiration pneumonia. ${ }^{11}$ The causes of vomiting are varied, but delayed gastric emptying is one of the main causes. Abdominal massage stimulates the vagus nerve and increases intestinal motility to prevent delayed gastric emptying. Abdominal massage has a mechanical reflex effect on the gut that increases peristalsis and promotes gastric emptying, which further prevents vomiting. ${ }^{3}$ In clinical practice, abdominal massage, as a nursing method to help patients accelerate gastric emptying, has a promotion value for preventing the occurrence of vomiting in patients. ${ }^{27}$

\section{Conclusions}

This study shows that abdominal massage can reduce the incidence of gastric residue, abdominal distension, gastric retention, and vomiting in ICU patients. When the intervention period is equal to 7 days, abdominal massage could reduce the abdominal circumference of ICU patients and improve their gastrointestinal function. This study proves that abdominal massage is effective. However, due to the inconsistency of the intervention cycle of abdominal massage among the studies, there is heterogeneity among the evaluation indexes in this study. At the same time, the quality evaluation of the included articles is B. So, in multicentered RCTs with large sample size is needed in the future to evaluate the effects of abdominal massage in ICU patients.

\section{Ethics approval}

Ethical issues are not involved in this paper.

\section{Conflicts of interest}

All contributing authors declare no conflicts of interest. 
1. Warren M. Abdominal massage may decrease gastric residual volumes and abdominal circumference in critically ill patients. Evid Based Nurs. 2016;19:76.

2. Sinclair M. The use of abdominal massage to treat chronic constipation. J Bodyw Mov Ther. 2011;15:436-445.

3. Tekgündüz K $\square$, Gürol A, Apay SE, Caner I. Effect of abdomen massage for prevention of feeding intolerance in preterm infants. Ital $J$ Pediatr. 2014;40:89.

4. Dehghan M, Fatehi Poor A, Mehdipoor R, Ahmadinejad M. Does abdominal massage improve gastrointestinal functions of intensive care patients with an endotracheal tube?: a randomized clinical trial. Complement Ther Clin Pract. 2018;30:122-128.

5. Seyyedrasooli A, Asadollahi M, Babaei H, Musavi $S$, Kiani Sh. Effects of abdominal massage and non-nutritive sucking on physiological parameters of preterm infants: a randomized clinical trial (RCT). Int J Pediatr. 2017;5:5167-5181.

6. Momenfar F, Abdi A, Salari N, Soroush A, Hemmatpour B. Studying the effect of abdominal massage on the gastric residual volume in patients hospitalized in intensive care units. J Intensive Care. 2018;6:47.

7. Huang XO. Effects of abdominal massage combined with postural intervention on gastrointestinal function of preterm infants. Chin J Mod Nurs. 2017;23:506-508 (in Chinese).

8. Higgins J, Green S. Cochrane Handbook for Systematic Reviews of Interventions Version 5.1.0. London: The Cochrane Collaboration; 2011.

9. Shaeri M, Ghadami A, Valiani M, Armanian AM, Amini Rarani S. Effects of abdominal massage on feeding tolerance in preterm. Int $J$ Pediatr. 2017;5:4503-4510.

10. Kahraman BB, Ozdemir L. The impact of abdominal massage administered to intubated and enterally fed patients on the development of ventilatorassociated pneumonia: a randomized controlled study. Int J Nurs Stud. 2015;52:519-524.

11. Uysal $N, E \square$ er $\square$, Akpinar $H$. The effect of abdominal massage on gastric residual volume: a randomized controlled trial. Gastroenterol Nurs. 2012;35:117-123.

12. Huang P. Clinical significance of abdominal massage nursing for patients with enteral nutrition. Mod Digest Interv. 2017;4:574-576 (in Chinese).
13. Lyu HL, Ni YH, Hu LF, Lin M. Effect of abdominal massage on gastric retention in patients with enteral nutritional crisis. Nurs J Chin PLA. 2014;18:26-28 (in Chinese).

14. Ge ZH, Lu GY, Gao DF. Effect of abdominal massage on gastric retention after enteral nutrition in comatose patients. Guangdong Med J. 2013;34: 2431-2433 (in Chinese).

15. Zhou BB, Yang JL, Yuan YL, He JF. Effect of abdominal massage on recovery of gastrointestinal function in patients with severe craniocerebral injury with indwelling nasointestinal tube. Chin Gen Pract Nurs. 2016;14:1112-1113 (in Chinese).

16. Peru N, Malgras B, Pocard M. Left anterolateral thoracotomy with cross-clamping of the descending thoracic aorta and open cardiac massage to control massive intra-abdominal bleeding. J Visc Surg. 2018;155:407-411.

17. Harrington KL, Haskvitz EM. Managing a patient's constipation with physical therapy. Phys Ther. 2006;86:1511-1519.

18. Liu Z, Sakakibara R, Odaka T, et al. Mechanism of abdominal massage for difficult defecation in a patient with myelopathy (HAMTSP). J Neurol. 2005;252:1280-1282.

19. McClurg D, Hagen S, Hawkins S, Lowe-Strong A. Abdominal massage for the alleviation of constipation symptoms in people with multiple sclerosis: a randomized controlled feasibility study. Mult Scler. 2011;17:223-233.

20. Liu XZ, CAI ZP, Shi GL. Effect observation of massage on improving success rate of blind insertion of nasointestinal tube. Med J Chin People Health. 2010;22:2804-2805 (in Chinese).

21. Elpern EH, Stutz L, Peterson S, Gurka DP, Skipper A. Outcomes associated with enteral tube feedings in a medical intensive care unit. Am J Crit Care. 2004;13:221-227.

22. Adam S, Batson S. A study of problems associated with the delivery of enteral feed in critically ill patients in five ICUs in the UK. Intensive Care Med. 1997;23:261-266.

23. Mentec H, Dupont H, Bocchetti M, Cani P, Ponche F, Bleichner G. Upper digestive intolerance during enteral nutrition in critically ill patients: frequency, risk factors, and complications. Crit Care Med. 2001;29:1955-1961.

24. Montejo JC. Enteral nutrition-related gastrointestinal complications in critically ill patients: a 
multicenter study. The Nutritional and Metabolic Working Group of the Spanish Society of Intensive Care Medicine and Coronary Units. Crit Care Med. 1999;27:1447-1453.

25. Kozeniecki M, Pitts $H$, Patel JJ. Barriers and solutions to delivery of intensive care unit nutrition therapy. Nutr Clin Pract. 2018;33:8-15.
26. Heydari A, Emami Zeydi A. Is gastric residual volume monitoring in critically ill patients receiving mechanical ventilation an evidence-based practice? Indian J Crit Care Med. 2014;18:259-260.

27. Tao N. Effect of abdominal massage on vomiting in patients with enteral nutritional crisis. Latest Med Info World. 2017;17:42 (in Chinese). 